\title{
A Recent Review of Learning Progressions in Science: Gaps and Shifts
}

\author{
Lei Liu, Teresa Jackson \\ Educational Testing Service, Princeton, USA
}

How to cite this paper: Liu, L., \& Jackson, T. (2019). A Recent Review of Learning Progressions in Science: Gaps and Shifts. The Educational Review, USA, 3(9), 113-126.

http://dx.doi.org/10.26855/er.2019.09.001

*Corresponding author: Lei Liu, $\mathrm{PhD}$, Student and Teacher Research Center, Educational Testing Service, Princeton, USA.

Email: Lliu001@ets.org

\begin{abstract}
A learning progression is a road map that shows how a student's qualitative understanding of particular ideas or practices is likely to change with appropriate instruction. An important goal of the LP approach is to align curriculum, instruction, and assessment to support students' learning. In 2009, LP research was pushed to its peak and placed in a prominent role in the national discussion on science education. The goal of our review is to analyze papers published in top journals between 2009 and 2018 to identify recent shifts in science LP research and how they address major gaps and critiques. In particular, we will begin by summarizing recent research focused on the challenges of using LPs in assessment and will identify key gaps in the LP research relevant to that area. We will then describe the methodology that we used to identify and evaluate the literature that addresses these gaps. Finally, we conclude with a discussion of the shifts in LP research as well as issues and implications for future LP research.
\end{abstract}

\section{Keywords}

Learning progression; Science learning and teaching; Science assessment; Formative assessment

\section{Introduction}

Learning progressions (LPs) in science have been defined as "empirically grounded and testable hypotheses about how students' understanding of, and ability to use, core scientific concepts, explanations, and related scientific practices grow and become more sophisticated over time, with appropriate instruction" (Corcoran, Mosher, \& Rogat, 2009, p. 20). Essentially, an LP is a road map that shows how a student's qualitative understanding of particular ideas or practices is likely to change with appropriate instruction (Alonzo, Benus, Bennett, \& Pinney, 2009; Bravo-Torija \& Jiménez-Aleixandre, 2018; Duncan \& Hmelo-Silver, 2009; Fulmer, 2015). The term progression implies a continuous, sequential movement from novice or naïve understanding towards more sophisticated expert thinking and reasoning within a discipline. An LP often includes the end points (upper anchor) as the ultimate learning goals, the entry level for the majority of students (lower anchor), and intermediate steps reflecting levels of integration or common stages that characterize the development of student thinking. There may be intermediate steps that are non-canonical but are stepping stones to canonical ideas. Given LPs' focus on student knowledge and thinking, LPs are considered promising tools for instruction and assessment. This review analyzes recent publications in top journals to identify recent shifts in science LP research to help address gaps or critiques on previous LP research and discuss implications for using LPs in assessment.

An important goal of the LP approach is to align curriculum, instruction, and assessment to support students' learning around the most generative and core ideas/practices that are central to the discipline and connect learning over time (Duschl, Maeng, \& Sezen, 2011). Researchers have articulated LPs for different grade levels, topics, and aspects of science. Some LPs have focused on the conceptual understanding of a topic, such as atomic-molecular theory (e.g., Smith, Wiser, Anderson, \& Krajcik, 2006) or celestial motion (e.g., Plummer \& Slagle, 2009). Others have focused 
on science practices (e.g., engagement in modeling, Schwartz et al., 2009) while some have moved beyond simply describing LPs and have begun to design supporting materials for LPs, including assessment instruments (Liu, Rogat, \& Bertling, 2013; Wilson, 2009), curricula, and instructional strategies (Duncan, Rogat, \& Yarden, 2009). As such, it is clear that learning progressions in science is an evolving field - a field that has gained more attention in the last decade. LPs are developed, articulated, and refined based on evidence from available research, including cognitive research, content-specific research, and learning sciences research. The cognitive research provides a basis for general learning descriptions. The content-specific research uncovers indicators of how conceptual understanding develops through the synthesis of science learning and common misconceptions. The learning sciences research provides opportunities to explore how learning actually progresses in authentic instructional contexts, thus offering possibilities to refine or fill in gaps in the existing hypothetical LPs. It is important to note that LPs should not be a best guess about how curriculum should develop, but should be evidence-based hypotheses of how learning develops. Therefore, LPs can serve as a guide for educators as they design instruction and assessment, and monitor students' progress toward the targeted levels of understanding and ability.

Well-articulated LPs should provide sufficient clarity to design assessments that can reveal a meaningful set of skills or concepts ranging from novice to expert (Corcoran et al., 2009). The assessment data should also support capturing student understanding and helping to locate that understanding along the LPs, tracking progress over time, and identifying gaps in the LPs (Smith et al., 2006). Summative assessments should function as technically adequate measures of what students know and can do, pointing towards targets for follow-up formative assessments, which should positively affect teaching and learning. Formative assessment tasks - used as a part of the instructional process - should help teachers plan instruction both prior to summative assessment by identifying competencies that require strengthening and after summative assessment by confirming competencies needing further attention. The formative assessment materials should also help teachers modify instruction in order to support students' progress in learning and provide feedback to students so that they can understand more clearly what they need to do in order to make progress (Duncan \& Rivet, 2013).

The 2007 report Taking Science to School (NRC, 2007) introduced LPs as a potential basis of high quality curriculum development as a consolidation of decades of prior research on student thinking, and led to a burst of LP work since then. In 2009, LP research was pushed to its peak and placed in a prominent role in the national discussion on science education because of several events: a dedicated conference-Learning Progressions in Science Conference (LeaPS; Alonzo \& Gotwals, 2009); a special edition issue in the Journal of Research on Science Teaching (Duncan \& HmeloSilver, 2009); and a report produced by a working panel which identified and discussed LPs from at least twenty different research projects to define a common set of guidelines for future LPs (Corcoran et al., 2009). In 2013, with the arrival of the Next Generation Science Standards (NGSS), LPs were promoted as a new way to teach and learn science. In the same year, an ETS Science competency model was also developed and adopted the notion of LPs as promising guiding principles for assessment design (see Liu et al., 2013).

Some promising uses of LPs have been acknowledged including the possibility that they can: (a) help inform the design of assessments to elicit what students know and are able to do; and (b) provide actionable information to teachers and guide their instructional next steps (Bennett, 2010; Liu et al., 2013). Ideally, the development of LPs should incorporate assessments that place students on a scale defined by research on how students learn (Shin, Stevens, Short, \& Krajcik, 2009). The assessments should attempt to measure complete understanding of a topic, assessing students' understanding of big ideas as well as the connections between related concepts (Smith et al., 2006). Because one of the guiding principles states that LPs go hand-in-hand with well-designed and aligned assessments (both formative and summative, Duncan \& Rivet, 2013), LPs can be used in conjunction with assessments. In addition, LPs can also provide support for planning and modifying instruction, designing and using ongoing assessments or assessment probes to locate student understanding along the learning continuum and to monitor individual or group progress over time.

As many states are still in the early stages of adopting NGSS in science instruction and curriculum, some may question whether it is too soon and ambitious to think about NGSS assessment. The National Academies Press (NAP) recently released Developing Assessments for the Next Generation Science Standards, a report from the National Research Council Committee on Developing Assessments of Science Proficiency in K-12. The report contains recommendations for policy makers and assessment developers. It proposes key characteristics of NGSS-aligned assessments and states an explicit requirement of gathering information regarding how far students have progressed along a defined sequence of learning (Pellegrino Wilson, Koenig, \& Beatty, 2014). However, questions still remain regarding whether there is 
sufficient research to support the assessment development effort. The goal of our review is to analyze papers published in top journals between 2009 and 2018 to identify recent shifts in science LP research and how they address major gaps and critiques. In particular, we will begin by summarizing recent research focused on the challenges of using LPs in assessment and will identify key gaps in the LP research relevant to that area. We will then describe the methodology that we used to identify and evaluate the literature that addresses these gaps. Finally, we conclude with a discussion of the shifts in LP research as well as issues and implications for future LP research.

\section{Challenges of Using LPs in Assessment and Gaps in LP Research}

Although LPs appear to be promising tools to align curriculum, instruction, and assessment, scholars pointed out that there were great challenges associated with using LPs for instruction and assessment purposes. It is demanding to develop high-quality assessments that can measure the depth and breadth of knowledge, practice, and crosscutting ideas. Most assessments used in developing and validating LPs consist of traditional multiple-choice questions (e.g., Briggs, Alonzo, Schwab, \& Wilson, 2006), interviews and written assessments (e.g., Heritage; 2008; Heritage, 2007; Hess, 2008; Stephens \& Story, 2000), or a mix of multiple-choice questions and open-ended items drawn from largescale standardized tests (e.g., Schmidt, Houang, \& Cogan, 2002). Although multiple-choice questions can be designed to reveal common naïve ideas about the topic at hand quickly and, thus, may be used to locate students' performance along a LP, such can measure only some types of learning and do not allow sufficient opportunities for students to do science, which is encouraged in transformational teaching to maximize students' development (Slavich, 2005). For other common item types, such as interviews and constructed-response items, which may provide richer information about student thinking, teachers often have difficulty scoring and interpreting student responses. Therefore, teachers will need support to make inferences about what students know in a timely manner.

Some of the challenges associated with using LPs in assessment may be due to the gaps in the LP research. Although there has been a proliferation of science LP research identified by several LP reviews conducted in the latter part of the last decade (Corcoran et al., 2009; Duschl, Schweingruber, \& Shouse, 2007; Hammer \& Sikorski, 2015), these works have also highlighted the existing gaps in LP research.

\subsection{Gap 1: Limited Number of LPs}

Corcoran et al.'s review (2009) shows that a limited number of hypothetical LPs have been developed, and even fewer LPs have been developed that span all grades in school $(\mathrm{K}-12)$. Moreover, only a small proportion of hypothetical LPs have been tested and validated. There certainly are not enough hypothetical LPs to cover all of the current standards, especially in the earth and planetary sciences. There were more hypothetical LPs in the life sciences, particularly in the areas of ecology and evolution, and the physical sciences (e.g., the structure of matter). In the physical sciences, there was substantial research investigating student alternative conceptions and conceptual change underlying initial hypothetical LPs for the structure and behavior of matter in K-8 (e.g., Smith et al., 2006). Validating work was conducted at the elementary and middle school levels (Stevens, Delgado, \& Krajcik, 2010). Very little work has been done to examine the interactions between any two hypothesized LPs; therefore, this interaction is also a major gap (Corcoran et al., 2009). Furthermore, little research has been conducted to better understand the interactions between specific learning progressions in science and those in mathematics, reading, or writing.

\subsection{Gap 2: Lack of Integrated LPs}

Some scholars (e.g., Hammer \& Sikorski, 2015) argued that the mainstream LP research failed to address complexity of cognition and learning. For example, the NGSS explicitly describes science learning as three-dimensional. Parallel with developing conceptual knowledge, students' abilities to engage in and understand particular science practices, such as constructing models, constructing evidence-based explanations, designing investigations, or constructing arguments also grows in sophistication over time. However, the mainstream LP research mostly focused on the exploration of one dimension of development. A few researchers have developed LPs that foreground the development of science practices, such as the work by Schwarz and colleagues on modeling (Schwarz et al., 2009) or on explanations (Berland \& McNeill, 2010), but, again, there are only a few learning progressions focused on particular science practices. To support policy that recommends student engagement in these science practices (NRC, 2011; the NGSS Lead States, 2013), progressions for such practices must be created. In this case, the term progression would refer to students' increasing capacities to engage productively in the practice (e.g., developing more sophisticated models) as well students' increasing abilities to reflect on the nature of the practice (e.g., developing more sophisticated epistemological understandings of models). 
Some researchers have developed progressions that intimately connect the development of content knowledge and the development of students' abilities to engage in science practice (see Lehrer \& Schauble's [2004] work on data modeling and biodiversity); however, this work is limited to the early and middle elementary grades. In addition, Hammer and Sikorski (2015) critiqued that LP research needs to "account for variability in students' ideas and whether curriculum informed by LPs will support or work to reduce that variability" (p. 429).

\subsection{Gap 3: Lack of Teacher Support}

Another gap in LPs that researchers frequently argue is that LPs do not necessarily produce actionable information that teachers can use to adjust next instructional steps (see Alonzo \& Gearhart, 2006; Heritage, 2008; Heritage, Kim, Vendlinski, \& Herman, 2008). Teachers need great support to effectively use LPs to take appropriate actions in practice to address the challenges in student learning. LPs may in some cases provide detailed descriptions of student learning; however, most of them do not provide the support teachers need to adjust their instruction. One example is that most LPs are represented in linear or hierarchical formats, although researchers often acknowledge that students may follow different and nonlinear paths (Corcoran et al., 2009). The linear representation makes it difficult for teachers to understand the multiple paths students might take in learning, therefore presenting challenges in taking appropriate actions in next-step instruction. In addition, teachers are more familiar with dichotomous (i.e., correct or incorrect) interpretations of student ideas and, consequently, need professional development to support making meaning of alternative or naïve ideas that might be productive to support the process of moving the student up the continuum described by the LPs.

The goal for the current paper was to conduct an analytical review of recent research on LPs in science with particular interest to see if there were efforts made to address the gaps in previous LP research. Our review focuses on science LPs in $\mathrm{K}-12$ settings. To narrow down the review scope and avoid redundant messages from previous reviews, our review is more on current thinking in LP research since 2009 through 2016.

\section{Review Scope and Purposes}

The focus of this review is on recent LP research (published between 2009 and 2018) related to $\mathrm{K}-12$ science disciplinary core ideas, practices, and crosscutting concepts as part of NGSS. The review aims to explore if the previously identified gaps in LP research have been addressed in recently published LP work. This section describes the methodology that we used to identify and select papers relevant to our review goal.

\subsection{Paper Selection, Review Parameters, and Search Results}

To provide an overview of the current research and illustrate the field of LP in K-12 science education, the paper focuses on major well-established journals in science education, ranging from 2009 to 2018. A focus on key journals likely best reflects changes or progress in the field (Chen \& Hirschheim, 2004); it provides a snapshot of the current field of research and facilitates the selection process by reducing the number of articles to be examined. Selecting articles from well-established journals more likely ensures the quality of the reviewed articles. For our purpose, top journals relevant to science education were considered (based on the SCImago Journal and Country Rank in 2014), including: Journal of Research in Science Teaching, Review of Educational Research, Science Education, Studies in Science Education, American Educational Research Journal, Journal of Educational Psychology, Learning and Instruction, Educational Researcher, and Journal of the Learning Sciences.

Publications from four topic areas were examined: LPs of disciplinary topics in science, LPs of science practices, LPs of crosscutting concepts in science, and LPs in general K-12 science education. Key words related to these four topics were used for searching articles to ensure that LPs were a key research concept and/or applied in the published papers. In addition, in order to include papers that focused on development and validation of LPs, the key word LP methods was also used for searching papers.

The selection process involved a systematic approach to identify and select articles in a transparent way. The selected journals were searched and reviewed to determine relevance, using predefined criteria:

- Articles should deal specifically with aspects of LPs.

- Articles should concern $\mathrm{K}-12$ science education.

- Articles should have been published between 2009 and 2018. 
Each of the selected top ranked journals were searched using the EBSCOHost and JSTOR databases, considering the restricted years of publication and other criteria noted above. A database of 135 relevant articles was established. After a closer review of the abstracts and coding of the relevance level for each paper, 57 out of the 151 papers were selected as highly pertinent to the review purpose. Those 57 articles of interest, whose titles are listed in the Appendix, were reviewed in detail and summarized in a database with specific information about the proposed research questions/goals, methodology, sample, assessment, scoring, revision processes, results, and conclusions. This database allowed for an initial look at any emerging themes in Learning Progression research as well as a glance into the areas that still need additional work and refinement.

In the following section, we report our review findings in terms of: LPs in science and coverage of topics in standards, integration of LPs to capture the complex nature of science learning, and support of teachers' use of LPs in practice. We conclude with a discussion and implications for future research.

\section{Review Findings}

Our analytical review of recent publications on LPs in science focuses on if and how recent LP research has started addressing the major critiques on LP research, namely limited number of LPs to cover the breadth of the NGSS, lack of integrated LPs to address the complexity of cognition and learning, and challenges in teacher implementation of LPs in instruction. In this session, we discuss findings from our review corresponding to the above-mentioned three major critiques.

\subsection{LPs in Science and Coverage of Topics in Standards}

The recent release of the NGSS refers to LPs as promising tools to support multi-dimensional, coherent, and progressive science learning. Previous reviews of LPs concluded that there certainly are not enough validated LPs to cover all the current NGSS standards (Corcoran et al., 2009; Liu et al., 2013). Previous reviews of LPs identified that the breadth of LPs, particularly in science, is quite limited. In our review, we coded the topics of all LPs developed or used in the selected papers between 2009 and 2015. The coding scheme includes five key topics covered by these papers. The first three topics are the three key dimensions in NGSS, namely core ideas, science practices, and crosscutting concepts. The goal of papers categorized in these categories was mainly to describe the development and/or validation of a LP targeting a topic that falls under one of the three NGSS dimensions: disciplinary core ideas, science and engineering practices, and crosscutting concepts.

For the dimension of core science ideas, we found that recent efforts since 2009 were focused on developing LPs for various topics across different science domains, ranging from force and motion (Alonzo \& Steedle, 2009; Fulmer, 2014), matter and atomic molecular (Adadan, Trundle, \& Irving, 2010; Liu, et al., 2013; Morell, Collier, Black, \& Wilson, 2017; Smith, Wiser, Anderson, \& Krajcik, 2006; Steven, Delgado, \& Krajcik, 2010) and magnetism (Cheng \& Brown, 2015) in the domain of Physical Sciences, to genetics (Duncan, Rogat, \& Yarden, 2009; Duncan \& Tseng, 2011) and energy in ecosystems (Hermann-Abell \& DeBoer, 2018; Jin \& Anderson, 2012; Lee \& Liu, 2012; Neumann, Viering, Boone, \& Fisher, 2013) or water in ecosystems (Gunckel, Govitt, Salinas, \& Anderson, 2012; Forbes, Zagori, \& Schwarz, 2015) or ecosystems (Magntorn \& Hellden, 2007; Manz, 2012; Mohan, Chen, \& Anderson, 2009; ) and natural selection or evolution (Lerher \& Schauble, 2012; )in the domain of Life Sciences, and celestial motion (Plummer, 2014; Plummer \& Krajcik, 2010; Plummer \& Maynard, 2014) in the domain of Earth and Space Sciences. For the dimension of science and engineering practices, we found there were increasing number of research studies focusing on developing LPs for this dimension, which often were contextualized in certain disciplinary ideas. The LPs focused on the practice dimension include describing student paths of understanding and applying a specific practice, such as modeling (Manz, 2012; Schwartz et al., 2009), constructing scientific explanations (Braaten \& Windschitl, 2011; Kang, Thomson, \& Windschitl, 2014; Songer \& Gotwals, 2012; Songer, Kelcey \& Gotwals, 2009; Yao \& Guo, 2018), scientific argumentation (Berland \& McNeill, 2010; Bravo-Torija \& Jiménez-Aleixandre, 2017; Osborne, Henderson, MacPherson, Szu, Wild, \& Yao, 2015), non-linear reasoning (Hovardas, 2016), and analogical reasoning (Rivet, Kastens, 2012). For the third dimension of crosscutting concepts in NGSS, there were fewer topics covered in recent LP research, including topics of energy (Jin \& Anderson, 2012; Lee \& Liu, 2010), patterns (Wyner \& Doherty, 2017), structure and function (Danish, 2004), and systems thinking (Danish, 2014).

Our review also revealed a good number of LP research studies focusing on the methodology of developing and validating LPs. Papers in this category focus on specific methods applied to develop and refine LPs. For example, 
Mark Wilson (2009) described a method of using a construct map for charting out student understanding in LPs as one possible, straightforward way of thinking about and assessing a learning progression. Finally, there were some research focusing on the implementation of LPs, for example, using LPs in assessment and instruction. This is a broad category with papers that discusses how LPs can be measured through assessments and how tools were created to support teachers' use of LPs or the concept of LPs in their instruction. For example, Braaten and Windschitl (2011) created a learning progression developed to help teachers reflect on their own learning and their classroom teaching practices, along with an Explanation Tool to serve as a powerful heuristic helping to organize teachers' thoughts about scientific explanations in their classrooms.

Although counting the exact number of topics covered by recent LPs is not the intent of this review, it must be noted that there is a trend in LP research that shows the expansion in topics related to NGSS; however, the existing examples of progressions vary in the grain size of the big ideas and the number of levels they postulate (e.g., Alonzo \& Steedle, 2009; Berland \& McNeill, 2010; Duncan et al., 2009; Plummer \& Krajcik, 2010; Schwarz et al., 2009; Songer et al., 2009). Many of these LPs are new topics, such as the structure, behavior, and function of the honeybee system (a crosscutting concept, Danish, 2014), celestial motion (a core idea, Plummer \& Maynard, 2014), and scientific argumentation (a science practice, Berland \& McNeil, 2010).

Among all 44 reviewed papers, there are 16 papers mainly targeting the development of LPs in the dimension of core ideas, nine papers mainly targeting science practices, and four papers focusing mostly on crosscutting concepts. Some of these papers were coded for more than one dimension as they tended to address the integrated issues. For example, the two papers authored by Nancy Songer and her colleagues were double coded in both core ideas and practices because their LPs attempted to address the interconnection between content and the science practice of constructing explanations. In addition to the three dimensions of science, four papers focused on the methodology of developing and validating LPs, and 13 papers focused on topics related to assessments and instruction that use LPs as the key principles. When these categories were taken into account, more overlap appeared. For example, a paper by Alonzo and Steedle (2009) mainly described the process of developing an LP for force and motion, however, they also acknowledged the crosscutting nature of the core idea in that student LP levels may be impacted by different contexts. In addition, they described in great detail the methods that they used for developing assessments to measure students' levels on a LP ordered multiple-choice (OMC). OMC items include response options, each of which corresponds to a level of the LP so that a student's responses to a set of items could be used to characterize the specific level of student understanding of the target concept. Therefore, the Alonzo and Steedle (2009) paper was coded in four categories, namely core ideas, crosscutting concepts, methodology, and assessment/instruction.

\subsection{Integrations in LPs to Capture the Complexity of Science Learning}

As discussed earlier, previous reviews on LPs critiqued that researchers frequently ignore the complex nature of science learning which often integrates multiple dimensions of knowledge and skills and requires social interactions (with peers and teachers) in the progressive process of learning. In our review of recent publications on LPs, we found that most researchers at least acknowledged the integrated nature of learning, and some work explicitly emphasized the multi-dimensional nature of science learning. For example, Manz (2012) stressed the need to support the simultaneous coordinated development of both practice and knowledge when engaging students' in scientific activities. In this study, Manz investigated how students developed ecological knowledge through the modeling practice and associated other practices, and summarized that ".... What changed over the course of the year was when and how they (students) sought to use these ideas to pose questions and to make and defend new claims..." (p. 1099). This statement stresses the integration of the practices of modeling, asking questions and constructing scientific explanations with the conceptual understanding of scientific concepts.

Plummer and Krajcik's (2010) findings reiterated this belief about the complexity of learning, noting in their study that "traditional instruction and observations of the world are not sufficient to help students move beyond an intermediate level of understanding" (p. 783) without engaging students in application of science practices in instruction. Duschl et al. (2011) echoed these statements, noting that, "The shift from science as inquiry processes and skills to science as a set of practices is very significant for rethinking the nature of longitudinal studies and the design of curriculum, instruction and assessment models" (p. 172). Wyner and Doherty (2016) developed a LP for three-dimensional learning of the patterns of evolution to explore the interplay between scientific practice and conceptual learning in the evolutionary relatedness LP. Specifically, they used the scientific observation practice framework together in categorizing, relatedness, and length of change over time, to build understanding of the patterns of evaluation in living organism. 
Other authors (see Alonzo \& Steedle, 2009) have also acknowledged the multi-dimensional competencies in play during the science learning process. That is, although most LPs development remain uni-dimensional, a majority of the papers that we reviewed address the complex nature of cognition and learning when describing the use of LPs in practice.

The results affirm that expertise resides not in the recitation of principles, but, rather, in imposing conceptual structure to navigate complexity and opacity (Hmelo-Silver, Marathe, \& Liu, 2007; Magntorn \& Helldén, 2007). Plummer (2014) used an LP framework to make the case that spatial reasoning is a key element of what progresses as students engage in more sophisticated ways of reasoning about astronomy. Rudsberg et al. (2013) utilized discourse as an approach to make it possible to investigate both the learning of knowledge content and the learning of the argument constructed. They believed that the processes undertaken by students in their social interactions could generate knowledge about which factors influence the learning results and make it possible to clarify the students' use of knowledge in the argumentative discussion. Jin and Anderson (2012) also stressed the importance of the multidimensional nature of science knowledge when describing their LP for energy. Therefore, this trend of integrating science practices into conceptual LPs development and validation suggests that student progression towards more sophisticated conceptual understanding should be supported by participating in complex scientific practices, instead of being taught the concepts in isolation from practice or being initiated only into simple forms of practice such as observation or categorization (Lehrer, Schauble, Carpenter, \& Penner, 2000; Louca, Elby, Hammer, \& Kagey, 2004; Metz, 1995, 2011).

\subsection{Supporting Teacher Use of LPs in Practice}

Given all the challenges in implementing an LP approach to transform instruction, we found there was an increasing number of studies that particularly focused on documenting how teachers applied LPs in classrooms, the challenges they faced during their implementation, and efforts to find solutions to address those challenges. This need to support instruction to address the integrated nature of science and to support teachers to use LPs has been stressed by researchers. Kang et al. (2014) stated that with the new reform emphases on science as practice, teachers need sufficient scaffolding around implementing practice-centered instruction and using assessments that measure students' abilities to take up the conceptual, social, and epistemic dimensions of disciplinary work. Furtak (2012) noted that the promise of LPs for teacher development lies in providing teachers with a "pedagogical vision" that can guide their instruction decisions. It has been a long ongoing challenge in science education to support and scaffold teachers' practice in facilitating students to develop more sophisticated scientific understanding. Furtak et al. (2014) explicitly expressed that it was vital for researchers to explore how teachers employ information about how students learn and how assessment should be used for formative purposes to support their understanding and implementation of LPs. More recently, Alonzo (2018) asserted that LPs may support teachers' formative assessment practices, which posed great challenges to teachers. LPs provide a model of student cognition to aid teachers in a high-quality process of developing and interpreting student data. However, most teachers will need support to understand how LPs can server as support for framing, eliciting, interpreting, and responding to evidence of student thinking. It is evident that more work must be done to help teachers and students successfully participate in the practice of using LPs in teaching and learning. In our review, we found that there was an increase in LP studies focused on developing support for teachers to use LPs in adjusting instruction next steps. These studies tend to fall into one of the two deriving lines of research: (a) assessment as a tool to generate useful data to support the use of LPs and (b) developing professional programs or tools to support teacher use of LPs.

Several studies that we reviewed discussed strategies related to creating appropriate assessments to generate useful data for developing and using LPs. Some of the authors discussed how teachers might find such data useful and thus support their use of LPs in instruction. For example, Songer et al. (2009) reported that if they had used only standardized assessment instruments to evaluate program effects in their study, they would have had much more limited information on character and advances and improvements in complex tasks. Similarly, Gotwals and Songer (2013) stated, “... Our results illustrate the importance of gathering multiple sources of data about what students know and can do when gathering evidence about a learning progression and learning progression based assessment items. If we were to only rely on the results from our difficulty analysis, we would not have examined the nuance in students' abilities to use reasoning and evidence. Thus, especially in these times of the early work on learning progressions, it is imperative that we gather rich and varied sources of data about the nuances of students' understanding and learning through written work, think-alouds, interviews, and other data sources (such as curricular interventions)" (p. 623). Lee and Liu (2010) suggested that pursuing single correct ideas for individual science problems may be detrimental in efforts to understand highly integrated concepts (e.g., energy conservation). This is similar to Steedle and Shavelson's (2009) conclusion that "students cannot always be located at a single level of the learning progression... Consequently, learning progression 
level diagnoses resulting from item response patterns cannot always be interpreted validly" (p. 713).

In recent studies, Erin Furtak and colleagues have made great efforts to support teacher use of LPs in practice and to understand their challenges in doing so. Furtak and Heredia (2014) noted that LPs could be a useful tool provided to teachers to organize their instruction, although when presented with the materials "teachers struggled to balance it with the other information they had been provided" (p. 1014). Furtak (2012) found that one big challenge for teachers was that the LP helped them identify common misunderstandings, but it did not prepare them to respond to student ideas and adapt their instruction. Furtak (2012) suggested that LPs need to be accompanied by other supports to help teachers adapt their instructional practices. In a follow up study, Furtak and Heredia (2014) observed a dynamic between both tailored and ill-structured uses of the LP. According to this decomposition of the role of the LP, they concluded that there is no single method that fits all instructional communities. LPs are complex tools and teachers need to use LPs to uncover information about students' previous learning experiences and to provide a context for how assessment should be used for instructional or formative assessment purposes.

Other researchers also explored building possible scaffolds to support the practical use of LPs. Kang et al. (2014) explored the impact of the quality and combination of scaffolding types, which they found matters more than the number of scaffolds embedded in the assessments. Quality combinations include a contextualized phenomenon in addition to one or more of the other types of upper-level scaffolds. A contextualized phenomenon engages students in deep forms of reasoning to demonstrate in-depth explanation. For example, in an assessment about the seasons, contextualizing the generic phenomena of seasonal changes in different geographic regions (e.g., Samoa and Seattle) generates multiple variables that must be taken into account, such as relative distances of different parts of the earth from the sun, changes in the angles of the sunlight on the earth, penetration of light through layers of the atmosphere, and so forth. This contextualization prompts students to recognize the general model of seasonal change and then reason how this model plays out under different conditions.

In recent LP research, tools and professional development programs have been developed to accompany the implementation of LPs in classrooms. However, there are still high demands on research to further advance LP research to support the practical implementation of LPs. For example, Duncan and Rivet (2013) distinguished two types of student ideas, productive versus unproductive, that may be included in the description of LPs. Most LPs either do not make distinctions in student ideas, or only focus on describing productive (or useful) naïve ideas as stepping stones for knowledge construction and ignore the documentation of those unproductive ideas. Therefore, it is challenging for teachers to figure out how to use student ideas when implementing LPs. In addition, the number of pathways represented by a LP also matters in terms of supporting teacher use of LPs.

\section{Discussion and Implications for Future Research}

LPs hold great promise for the science education community due to their focus on how students learn interconnected core ideas and apply key science practices. LP research has advanced considerably in the last ten years and entered its prime time in 2009. The goal of this analytical review, with its focus on papers published in top journals between 2009 and 2018, was to identify recent shifts in LP research and how they addressed major gaps and critiques. The analysis started with an overview of the challenges of using LPs in assessment and gaps in LP research, then it continued with using evidence collected from the selected papers to articulate how recent LP research addressed the three major gaps in LPs and their implementation: the coverage of standards, addressing the complex nature of science learning, and challenges in teachers' use of LPs. Our review found that LP research has further advanced by broadening the topics across various dimensions in science learning. Such advancement is useful for informing standards and associated assessments; however, there is still a great gap to fill in order to have a full coverage of the complete NGSS competencies. Therefore, developing LP-based assessments and curriculum for the NGSS remains a challenge. Alonzo, Neidorf, and Anderson (2012) also discussed cautions in implementing an LP-based approach to large-scale assessment systems by arguing that LP-based assessment development requires an iterative process, while large-scale assessments often adopt pre-determined specifications.

Earlier in the paper, we discussed the existing gaps in LP research: (a) a limited number of validated LPs, (b) insufficient attention to the integrated nature of learning, and (c) the need for support for teachers. Our review found that recent publications on LPs indicate there are trends to address the above mentioned gaps in LP research. For example, there are more new topics covered in science in recent publications across the three NGSS dimensions. In addition, the majority of recent research acknowledged the complexity of learning and the multi-dimensional and integrated nature of science 
learning. Finally, more recent efforts have been focused on developing tools and support for teachers to use LPs as a conceptual tool to improve instruction. Although some LPs have been well validated and extend to all or part of middle school biology (e.g., the carbon cycle: see Mohan et al., 2009; food webs and food chains: see Gotwals \& Songer, 2010; Songer et al., 2009), the importance of validation was explicitly noted by several researchers in our review. For example, in 2011, Duschl et al. questioned "Which are the methods for validating or otherwise establishing learning progressions?" (p. 170). Likewise, many of the studies that were included in this review (see Alonzo \& Steedle, 2009; Duncan \& Hmelo-Silver, 2009; Duncan et al., 2009; Gotwals \& Songer, 2013; Hadenfeldt, Liu, \& Neumann, 2014; Johnson \& Tymms, 2011; Lee \& Liu, 2010; Mohan et al., 2009; Rudsberg et al., 2013; Shea \& Duncan, 2013; Steedle \& Shavelon, 2009) have highlighted the importance of longitudinal designs and/or the empirical validation of LPs. Although the importance has been recognized, there remains an underlying theme of the difficulty associated with this task. As Alonzo \& Steedle (2009) stated "Longitudinal studies of student learning in different curricular contexts are needed to fully validate any learning progression. All of this work takes time but is required to have confidence that the learning progression is a valid representation of the way in which student thinking develops" (p. 418).

In a similar vein, Berland and McNeill (2010) concluded that "Although an overarching goal of science education is for students to engage in argumentation in which they construct and justify knowledge claims and practice productive social interactions with their peers, these are not the norms of classroom science (Duschl et al., 2007). Learning progressions provide a tool to help students develop more complex ways of thinking about a practice, specifically scientific argument, across time (Smith et al., 2006). Each of the defined dimensions in our learning progression creates an opportunity for educators to support student progress in participating in argumentative discourse" (pp. 786-787).

We learned that many of the researchers whose studies were included in this review recognized the need for more research on practices. For example, Furtak (2012) reported that although learning progressions may have aided teachers in identifying misunderstandings, they did not help inform their instructional practices. Schwarz et al. (2009) noted that there are challenges associated when practice is integrated (and interactive) with underlying metaknowledge. Forbes et al. (2015) acknowledged that there have been efforts to provide models of integrated learning progressions, but very few have been developed at a level that integrates science concepts with science practices - a key component of NGSS individual standards. Although some have questioned (see Duschl et al., 2011) what perspectives about science practices should be adopted, researchers (see Manz, 2012) have concluded that the complexities and challenges associated with expanding practices are worth pursuing.

In addition, through reviewing recent LPs publications, we found that recent LP research attended to the complex nature of learning during both the development and validation processes, which was a key critique of previous LP research. For an LP to be useful for learning, it should be linked to the contemporary theories of how students learn, which advocate active engagement of science practices to develop deep scientific understanding. Although most existing LPs are grounded in students' prior knowledge, naïve ideas, and previous learning experiences, very few LPs addressed the integrated nature of science learning. Our review revealed that many LP researchers tended to integrate science practices into the use of the LPs (most of which focused on describing the progression of science concepts), and there is a growing number of LPs that focused on the "doing science" dimension as well. Anchoring the construction of core concepts in engagement of meaningful problem solving and investigation of the natural world can support reaching the goal of LPs to promote deep learning. Of course, there is no single LP that will be ideal for all children due to their differences in instructional backgrounds, various personal and cultural resources, and social and material environments. Looking forward, more work is needed to address the complex nature of science learning in LP research.

Finally, we were reminded of the importance of assessment. Assessments, at their best, will focus on students utilizing their knowledge in an effort to make their reasoning visible (Shin et al., 2009). Good assessments will attend not only to the context and features of items, but also will take into consideration how the context and features of particular items are related to the intermediary steps in a LP (Duncan \& Rivet, 2013). But to have solid assessment requires that teachers receive more support and preparation than what exists in the current system. To do this effectively would require great effort, time, and money; however, the potential benefits of educators fully understanding how learning moves across a domain, the relationships across disciplinary domains, and how instructional planning and assessment can be incorporated would be well worth it (Heritage, 2008).

In conclusion, Pellegrino has (2012) stated that “...this is an interesting moment in the history of science education in the U.S. A confluence of factors creates the opportunity for major changes in the teaching, learning, and assessment of science across $\mathrm{K}-16+$ " (p.839). After this analysis, in which we reviewed recent LP publications, identified existing 
gaps in LP research, discussed the challenges associated with teachers' usage of LPs in practice, presented information about the coverage of NGSS topics, and provided evidence of recent shifts in LP research to address the complex nature of science learning, it is clear that Pellegrino's (2012) description of this moment in science education is accurate. Although we have found that there have been many advances in this area of research, we also indicated that there are many gaps in the existing research base and that there is much more work to be done. Thus, our findings are in line with Manz (2012) who concluded, "There is much work yet to be done in understanding the complexities of this perspective on the development of content knowledge and determining how best to support teachers in orchestrating it" (p. 1102). The critical reviews that many scholars offered on LP work have helped advance the LP research trends to address identified gaps in the field.

\section{References}

Adadan, E., K. C., Trundle, \& K. E. Irving. (2010). Exploring grade 11 students' conceptual pathways of the particulate nature of matter in the context of multirepresentational instruction. Journal of Research in Science Teaching 47(8), 1004-1035.

Alonzo, A. C. (2018). An argument for formative assessment with science learning progressions. Applied Measurement in Education, 31(2), 104-112.

Alonzo, A. C., Gearhart, M. (2006). Considering learning progressions from a classroom assessment perspective. Measurement: Interdisciplinary Research and Perspectives, 4(1\&2), 99-108.

Alonzo, A. Neidorf, C., T., \& Anderson, C. W. (2012). Using learning progressions to inform large scale assessment. In Learning progressions in science: Current challenges and future directions, edited by Alonzo A. C. and A. W. Gotwals, 3-12. Rotterdam, The Netherlands: Sense Publishers.

Alonzo, A. C., \& Steedle, J. T. (2009). Developing and assessing a force and motion learning progression. Science Education 93(3), 389-421.

Bennett, R. E. (2010). Cognitively based assessment of, for, and as learning: A preliminary theory of action for summative and formative assessment. Measurement: Interdisciplinary Research and Perspectives, 8, 70-91.

Berland, L. K., \& McNeill, K. L. (2010). A learning progression for scientific argumentation: Understanding student work and designing supportive instructional contexts. Science Education 94(5), 765-793.

Braaten, M., \& Windschitl, M. (2011). Working toward a stronger conceptualization of scientific explanation for science education. Science Education 95(4), 639-669.

Bravo-Torija, B., \& Jiménez-Aleixandre, M. (2018). Developing an initial learning progression for the use of evidence in decision-making contexts. International Journal of Science and Math Education, 16, 619-638.

Briggs, D., Alonzo, A., Schwab, C., \& Wilson, M. (2006). Diagnostic assessment with ordered multiple-choice items. Educational Assessment 11(1), 33-64.

Chen, W., \& Hirschheim, R. (2004). A paradigmatic and methodological examination of information systems research. Information Systems Journal, 14(3), 197-235.

Cheng, M. F., and D. E. Brown. 2015. "The role of scientific modeling criteria in advancing students' explanatory ideas of magnetism." Journal of Research in Science Teaching 52(8): 1053-1081.

Claesgens, J., Scalise, K., Wilson, M., \& Stacy, A.. (2009). Mapping student understanding in chemistry: The perspectives of chemists. Science Education 93(1), 56-85.

Corcoran, T. B., Mosher, F. A., \& Rogat, A. (2009). Learning progressions in science: An evidence-based approach to reform. CPRE Research Report 63. Philadelphia: Consortium for Policy Research in Education.

Danish, J. A. (2014). Applying an activity theory lens to designing instruction for learning about the structure, behavior, and function of a honeybee system. Journal of the Learning Sciences 23(2), 100-148.

Duncan, R. G. \& Hmelo-Silver, C. E. (2009). Learning progressions: Aligning curriculum, instruction, and assessment. Journal of Research in Science Teaching, 46(6), 606-609. 
Duncan, R.G., \& Rivet, A. (2013). Science learning progressions. Science, 339(6118), 396-397.

Duncan, R. G., Rogat, A. D., \& Yarden, A. (2009). A learning progression for deepening students' understandings of modern genetics across the 5th-10th grades. Journal of Research in Science Teaching, 46(6), 655-674.

Duncan, R. G., \& Tseng, K. A. (2011). Designing project-based instruction to foster generative and mechanistic understandings in genetics. Science Education, 95, 21-56.

Duschl, R., Maeng, S., \& Sezen, A. (2011). Learning progressions and teaching sequences: A review and analysis. Studies in Science Education 47, 123-182.

Duschl, R. A., Schweingruber, H. A., \& Shouse, A. W. (2007). Taking science to school: Learning and teaching science in grades $K-8$. Washington DC: The National Academies Press.

Forbes, C. T., Zangori, L., Vo, T., \& Schwarz, C. V. 2(015). Studying the impact of a design intervention on 3rdgrade students' model-based explanations for water systems. Paper presented at the annual meeting of the National Association for Research in Science Teaching (NARST), Chicago, IL.

Fulmer, G. W. (2015). Validating proposed learning progressions on force and motion using the force concept inventory: Findings from Singapore secondary schools. International Journal of Science and Mathematics Education, 13(6), $1235-1254$.

Furtak, E. M. (2012). Linking a learning progression for natural selection to teachers' enactment of formative assessment. Journal of Research in Science Teaching, 49(9), 1181-1210.

Furtak, E. M., \& Heredia, S. C. (2014). Exploring the influence of learning progressions in two teacher communities. Journal of Research in Science Teaching 51(8), 982-1020.

Furtak, E. M., Morrison, D., \& Kroog. H. (2014). Investigating the link between learning progressions and classroom assessment. Science Education, 98(4), 640-673.

Gotwals, A. W., \& Songer, N. B. (2010). Reasoning up and down a food chain: Using an assessment framework to investigate students' middle knowledge. Science Education, 94(2), 259-281.

Gotwals, A. W., \& Songer, N. B. (2013). Validity evidence for learning progression-based assessment items that fuse core disciplinary ideas and science practices. Journal of Research in Science Teaching, 50(5), 597-626.

Gunckel, K. L., Covitt, B. A., Salinas, I., \& Anderson, C. W. (2012). A learning progression for water in socio-ecological systems. Journal of Research in Science Teaching, 49(7), 843-868.

Hadenfeldt, J. C., Liu, X., \& Neumann, K. (2014). Framing students' progression in understanding matter: A review of previous research. Studies in Science Education, 50(2), 181-208.

Hammer, D., \& Sikorski, T. (2015). Implications of complexity for research on learning progressions. Science Education, 99(3), 424-431.

Heritage, M. (2007). Formative assessment: What do teachers need to know and do? Phi Delta Kappan, 89, 140-145.

Hermann-Abell, C. F., \& DeBoer, G. E. (2018). Investigating a learning progression for energy ideas from upper elementary through high school. Journal of Research in Science Teaching, 55(1), 68-93.

Heritage, M. (2008). Learning progressions: Supporting instruction and formative assessment. Washington, DC: Council of Chief State School Officers.

Heritage, J., Kim, J., Vendlinski, T. P., \& Herman, J. L. (2008). From evidence to action: A seamless process in formative assessment? (CRESST Report 741). Los Angeles: University of California, Los Angeles, National Center for Research on Evaluation, Standards, and Student Testing (CRESST).

Hess, K. (2008). Developing and using learning progressions as a schema for measuring progress. Dover, NH: National Center for the Improvement of Educational Assessment. Retrieved from http://www.nciea.org/publications/CCSSO2 KH08.pdf

Hickey, D. T., \& Zuiker, S. J. (2012). Multilevel assessment for discourse, understanding, and achievement. The Journal of the Learning Sciences, 21(4), 522-582. 
Hmelo-Silver, C.E. \& Duncan, R. G. (2009). Special Issue: Learning Progressions. Journal of Research in Science Teachin, 46(6), 605-737.

Hmelo-Silver, C.E., Marathe, S., \& Liu, L. (2007). Fish swim, rocks sit, and lungs breathe: Expert-novice understanding of complex systems. Journal of the Learning Sciences, 16, 307-331.

Hoverdas, T. (2016). A leanring progression should address regression: Insights from developing non-liner reasoning in ecology. Journal of Research in Science Teaching, 53(10), 1447-1470.

Jin, H., \& Anderson, C. W. (2012). A learning progression for energy in socio - ecological systems. Journal of Research in Science Teaching, 49(9), 1149-1180.

Johnson, P., \& Tymms, P. (2011). The emergence of a learning progression in middle school chemistry. Journal of Research in Science Teaching, 48, 849-877.

Kang, H., Thompson, J., \& Windschitl, M. (2014). Creating opportunities for students to show what they know: The role of scaffolding in assessment tasks. Science Education, 98, 674-704.

Kind, P. M. (2013). Conceptualizing the science curriculum: 40 years of developing assessment frameworks in three large-scale assessments. Science Education, 97, 671-694.

Lee, H.S., \& Liu, O. L. (2010). Assessing learning progression of energy concepts across middle school grades: The knowledge integration perspective. Science Education, 94(4), 665-688.

Lehrer, R., \& Schauble, L. (2012). Seeding evolutionary thinking by engaging children in modeling its foundations. Science Education, 96, 701-724.

Lehrer, R., \& Schauble, L. (2004). Modeling natural variation through distribution. American Educational Research Journal, 41(3), 635-679.

Leher, R., \& Schauble, L. (2015). Learning progressions: the whole worlds is not a stage. Science Education, 99(3), 432-437.

Liu, L., Rogat, A., \& Bertling, M. (2013). A CBAL science model of cognition: Developing a competency model and learning progressions to support assessment development. ETS Research Report, RR-13-29. Princeton, NJ: Educational Testing Service.

Louca, L., Elby, A., Hammer, D., \& Kagey. T. (2004). Epistemological resources: Applying a new epistemological framework to science instruction. Educational Psychologist, 39 (1), 57-68.

Magntorn, O., \& Helldén, G. (2007). Reading new environments: students' ability to generalise their understanding between different ecosystems. International Journal of Science Education, 29(1), 67-100.

Manz, E. (2012). Understanding the codevelopment of modeling practice and ecological knowledge. Science Education, 96, 1071-1105.

Metz, K.E. (1995). Reassessment of developmental constraints on children's science instruction. Review of Educational Research, 65(2), 93-127.

Metz, K.E. (2011). Disentangling robust developmental constraints from the instructionally mutable: Young children's reasoning about a study of their own design. Journal of the Learning Sciences, 20(1), 50-110.

Mohan, L., Chen, J., \& Anderson, C. W. (2009). Developing a multi-year learning progression for carbon-cycling in socio-ecological systems. Journal of Research in Science Teaching, 46, 675-698.

Morell, L., Coller, T., Black, P., \& Wilson, M. (2017). A construct-modleing approach to develop a learning progression of how students understand the structure of matter. Journal of Research in Science Teaching, 54(8), 1024-1048.

National Research Council. (2007). Taking science to school: Learning and teaching science in grades $K-8$. Washington, DC: The National Academies Press.

National Research Council. (2011). A framework for K-12 science education: Practices, crosscutting concepts, and core ideas. Washington, DC: The National Academies Press. 
NGSS Lead States. (2013). Next generation science standards. Washington, DC: National Academies Press.

Neumann, K., Viering, T., Boone, W. J., \& Fischer, H. E. (2013). Towards a learning progression of energy. Journal of Research in Science Teaching, 50(2), 162-188.

Osborne, J. F., Henderson, J. B., MacPherson, A., Szu, E., Wild, A., \& Yao, S. (2016). The development and validation of a learning progression for argumentation in science. Journal of Research in Science Teaching, 53(6), 821-846.

Papadouris, N. (2012). Optimization as a reasoning strategy for dealing with socioscientific decision-making situations. Science Education, 96, 600-630.

Pellegrino, J. W. (2012). Assessment in science learning: Living in interesting times. Journal of Research in Science Teaching, 49(6), 831-841.

Pellegrino, J. W., Wilson, M., Koenig, J., \& Beatty, A. (2014). Developing assessments for the Next Generation Science Standards. Washington, DC: National Academies Press.

Plummer, J. D. (2014). Spatial thinking as the dimension of progress in an astronomy learning progression. Studies in Science Education, 50(1), 1-45.

Plummer, J. D., \& Krajcik, J. (2010). Building a learning progression for celestial motion: Elementary levels from an earth-based perspective. Journal of Research in Science Teaching, 47(7), 768-787.

Plummer, J. D., \& Maynard, L. (2014). Building a learning progression for celestial motion: An exploration of students' reasoning about the seasons. Journal of Research in Science Teaching, 51(7), 902-929.

Plummer, J.D., \& Slagle, C. (2009). Children explaining celestial motion: Development of a learning progression. Paper presented at the annual meeting of the National Association for Research in Science Teaching, Garden Grove, CA.

Rivet, A. E., \& Kastens, K. A. (2012). Developing a construct-based assessment to examine students' analogical reasoning around physical models in earth science. Journal of Research in Science Teaching, 49(6), 713-743.

Rudsberg, K., Ohman, J., \& Ostman, L. (2013). Analyzing students' learning in classroom discussions about socioscientific issues. Science Education, 97(4), 594-620.

Schmidt, W, Houang, R., \& Cogan, L. (2002). A coherent curriculum: The case for mathematics. American Education, 26(2), 1-18.

Schwarz, C. V., et al. (2009). Developing a learning progression for scientific modeling: Making scientific modeling accessible and meaningful for learners. Journal of Research in Science Teaching, 46(6), 632-654.

Shea, N. A., \& Duncan, R. G. (2013). From theory to data: The process of refining learning progressions. The Journal of the Learning Sciences 22, 7-32.

Shin, N., Stevens, S. Y., Short, H., \& Krajcik, J. (2009). Learning progressions to support coherence curricula in instructional material, instruction, and assessment design. Paper presented at the Learning Progressions in Science, Iowa City, IA.

Slavich, G. M. (2005). Transformational teaching. Excellence in Teaching, 5. Retrieved from http://www.georgeslavich. com/Transformational_Teaching.html.

Smith, C. L., Wiser, M., Anderson, C. W., \& Krajcik, J. (2006). Implications of research on children's learning for standards and assessment: A proposed learning progression for matter and the atomic molecular theory. Measurement: Interdisciplinary Research and Perspective, 4(1\&2), 1-98.

Songer, N. B., \& Gotwals, A. W. (2012). Guiding explanation construction by children at the entry points of learning progressions. Journal of Research in Science Teaching, 49(2), 141-165.

Songer, N. B., Kelcey, B., \& Gotwals, A. W. (2009). When and how does complex reasoning occur? Empirically driven development of a learning progression focused on complex reasoning about biodiversity. Journal of Research in Science Teaching, 46, 610-631.

Steedle, J. T., \& Shavelson, R. J. (2009). Supporting valid interpretations of learning progression level diagnoses. Journal of Research in Science Teaching, 46(6), 699-715. 
Stephens, D., \& Story, J. (2000). Assessment as inquiry: Learning the hypothesis-test process. Urbana, IL: National Council of Teachers of English.

Stevens, S. Y., Delgado, C., \& Krajcik, J. (2010). Developing a hypothetical multi-dimensional learning progression for the nature of matter. Journal of Research in Science Teaching, 47, 687-715.

Wilson, M. (2009). Measuring progressions: Assessment structures underlying a learning progression. Journal of Research in Science Teaching, 46(6), 716-730.

Wyner, Y. \& Doherty, J. H. (2017). Developing a learning progression for three-dimensional learning of the patterns of evolution. Science Education, 101, 787-817.

Yao, J., \& Guo, Y. (2018). Validity evidence for a learning progression of scientific explanation. Journal of Research in Science Teaching, 55(2), 299-317. 